\title{
A test of the salience asymmetry interpretation of the alcohol-IAT
}

Citation for published version (APA):

Houben, K. M. P. I., \& Wiers, R. W. H. J. (2006). A test of the salience asymmetry interpretation of the alcohol-IAT. Experimental Psychology, 53, 292-300. https://doi.org/10.1027/1618-3169.53.4.292

Document status and date:

Published: 01/01/2006

DOI:

10.1027/1618-3169.53.4.292

Document Version:

Publisher's PDF, also known as Version of record

Document license:

Taverne

Please check the document version of this publication:

- A submitted manuscript is the version of the article upon submission and before peer-review. There can be important differences between the submitted version and the official published version of record.

People interested in the research are advised to contact the author for the final version of the publication, or visit the DOI to the publisher's website.

- The final author version and the galley proof are versions of the publication after peer review.

- The final published version features the final layout of the paper including the volume, issue and page numbers.

Link to publication

\footnotetext{
General rights rights.

- You may freely distribute the URL identifying the publication in the public portal. please follow below link for the End User Agreement:

www.umlib.nl/taverne-license

Take down policy

If you believe that this document breaches copyright please contact us at:

repository@maastrichtuniversity.nl

providing details and we will investigate your claim.
}

Copyright and moral rights for the publications made accessible in the public portal are retained by the authors and/or other copyright owners and it is a condition of accessing publications that users recognise and abide by the legal requirements associated with these

- Users may download and print one copy of any publication from the public portal for the purpose of private study or research.

- You may not further distribute the material or use it for any profit-making activity or commercial gain

If the publication is distributed under the terms of Article $25 \mathrm{fa}$ of the Dutch Copyright Act, indicated by the "Taverne" license above, 


\title{
A Test of the Salience Asymmetry Interpretation of the Alcohol-IAT
}

\author{
Katrijn Houben and Reinout W. Wiers
}

Maastricht University, The Netherlands

\begin{abstract}
K. Rothermund and D. Wentura (2004) showed how Figure-Ground (FG) asymmetries produce effects on the Implicit Association Task (IAT), independent of associations. Here, the FG account was tested for the robust finding that drinkers show a negative alcohol-IAT effect while being positive on explicit measures. FG asymmetries were manipulated through familiarity of alcohol-IAT target categories and were assessed with visual search tasks. Supporting the FG account, the familiarity manipulation influenced the IAT effect in the expected direction, and the IAT effect correlated with FG asymmetries. Contrary to the FG account, however, the IAT effect was not reversed, and IAT effects were predicted by alcohol use but not by FG asymmetries. Hence, the FG account only partly explains the negative alcohol-IAT effect.
\end{abstract}

Keywords: Implicit Association Test, Figure-Ground asymmetries, implicit alcohol associations

In the seven years since its initial publication, the Implicit Association Test (IAT) (Greenwald, McGhee, \& Schwartz, 1998) has become a widely applied instrument to indirectly assess associations. The IAT is a speeded classification task in which words are classified into two-times-two categories: Two target categories (e.g., alcohol vs. soft drinks) and two attribute categories (e.g., positive vs. negative). In the critical IAT phases, the categories are assigned to two response keys in two different combinations (e.g., alcoholnegative vs. soft drink-positive and alcohol-positive vs. soft drink-negative). The IAT effect is the performance difference between these combinations, and the underlying assumption is that it is easier to combine concepts that are associated in memory than to combine concepts that are not or that are weakly associated (Greenwald et al., 1998). The IAT owes its popularity to its flexibility, large effect sizes, and good reliability (e.g., Bosson, Swann, \& Pennebaker, 2000; Cunningham, Preacher, \& Banaji, 2001; Nosek, Greenwald, \& Banaji, in press). Promising results were also found for its construct validity, with small but positive correlations between the IAT and corresponding self-report measures (see Hofmann, Gawronski, Gschwendner, Le, \& Schmitt, 2005) and good predictive validity (e.g., Poehlman, Uhlmann, Greenwald, \& Banaji, 2005).

Despite its popularity, many issues surrounding the IAT remain unresolved, including the interpretation of IAT effects. Whereas Greenwald et al. (1998) argue that IAT effects reflect the strength of implicit associations in memory, Rothermund and Wentura (2004) have proposed a nonassociative account of IAT effects, based on salience asymmetries. In a series of studies, they convincingly demonstrated that salience or "Figure-Ground" (FG hereafter) asymmetries can produce IAT effects independent of underlying associations. When categories forming a dimension in the IAT differ in salience, the salient category will act as a figure against the less salient background category. Consequently, Rothermund and Wentura have argued that performing the IAT should be easier for consistent mappings of the figure categories of both IAT dimensions than when one figure and one ground category are assigned to one response. Furthermore, Rothermund and Wentura showed that visual search tasks can be used to objectively assess FG asymmetries within IAT dimensions and that controlling for $\mathrm{FG}$ asymmetries can render the predictive validity of the IAT nonsignificant.

In a comment on Rothermund and Wentura (2004), Greenwald, Nosek, Banaji, and Klauer (2005) argued that Rothermund and Wentura based their evidence for the FG interpretation of the IAT upon nonstandard procedures that diminish the validity of the IAT. Specifically, they argued that Rothermund and Wentura have used artificial noncategories that are not representative of most IAT studies and that they used the conventional millisecond (ms) measure of IAT effects instead of the improved new D-measure (Greenwald, Nosek, \& Banaji, 2003). Greenwald et al. (2005) conducted two experiments using IATs that were closely modeled after the ones used by Greenwald et al. (1998), to further examine the validity of the FG asymmetry theory. Also, salience asymmetries were assessed with three measures modeled after the visual search task used by Rothermund and Wentura. Inconsistent with the FG hypothesis, the results did not show faster performance for consistent mappings of salient categories or correlations between the IAT and salience asymmetry measures. Greenwald et al. (2005) conclude that FG asymmetries are neither necessary nor sufficient to produce IAT effects.

In response to Greenwald et al. (2005), Rothermund, Wentura, and De Houwer (2005) stated that using nonstandard IAT procedures is in fact necessary to examine how the IAT functions in standard cases and to experimentally dissociate the influence from FG effects and associations which are typically confounded in standard IAT procedures. In addition, Rothermund et al. argued that reanalysis of the data reported by Rothermund and Wentura (2004) with the D-measure yielded the same pattern of re- 
sults as the analysis with the conventional ms measure. Rothermund et al. also stated that the null findings reported by Greenwald et al. are probably due to the task irrelevance of their salience manipulations and to the use of visual search tasks that differed from the one developed by Rothermund and Wentura.

\section{The Present Study}

The present study tested the FG interpretation for a puzzling, yet robust, IAT finding in alcohol research. Several alcohol-IAT studies have demonstrated that participants find it easier to combine alcohol and negative words in the IAT than to combine alcohol and positive words (De Houwer, Crombez, Koster, \& De Beul, 2004; Wiers, van de Luitgaarden, van den Wildenberg, \& Smulders, 2005; Wiers, van Woerden, Smulders, \& de Jong, 2002). Interestingly, the same participants indicated that they expected positive effects from drinking alcohol on explicit expectancy measures (Wiers et al., 2002). This negative alcoholIAT effect could be meaningful and representative of, for example, early negative experiences with alcohol (Rudman, 2004) or problems related to alcohol use (Wiers, Houben, Smulders, Conrod, \& Jones, 2006). Alternatively, this IAT effect could be an artifact of FG asymmetries in the IAT. According to Rothermund and Wentura (2004), negative stimuli generally act as figures against a positive background. Consequently, if alcohol is more salient than soft drinks (which often forms the contrast target category in the alcohol IAT), FG theory predicts faster performance for the combined mapping of alcohol and negative words than for the combination of alcohol and positive words, irrespective of meaningful associations.

This FG account of the alcohol IAT was tested in two ways. First, two positive-negative IAT versions were designed in which salience asymmetries between the alcohol and soft drink target categories were directly manipulated through familiarity of the category exemplars. The familiar alcohol IAT contrasted familiar alcoholic drinks with unfamiliar soft drinks, while the unfamiliar alcohol IAT presented unfamiliar alcoholic drinks versus familiar soft drinks. This manipulation should produce a salience asymmetry with the unfamiliar categories being more salient than the familiar categories (Rothermund \& Wentura, 2004). Accordingly, FG theory predicts faster performance for the combination of alcohol with negative words compared with the combination of alcohol with positive words in the unfamiliar alcohol IAT. However, in the familiar alcohol IAT, the FG account predicts a reversal of this IAT effect with faster performance for the combination of alcohol with positive words relative to the combination of alcohol with negative words. If, however, the negative alcohol-IAT effect reflects a meaningful association, the salience manipulation should not cause such a reversal of the IAT effect, and performance should be faster for the combination of alcohol with negative than for the combination of alcohol and positive in both IAT versions.

Second, visual search tasks (identical to the one used by Rothermund \& Wentura, 2004) were used to independently assess salience asymmetries within IAT dimensions. Negative words were expected to act as figures against a positive background in both IATs, whereas the alcohol and soft drink categories were expected to be figures only when they consisted of unfamiliar exemplars. The FG account predicts an influence of the central familiarity manipulation on IAT effects and expects a correlation between IAT effects and FG asymmetries. In addition, according to the FG account, FG asymmetries should predict IAT effects above self-reported alcohol use and alcohol-related problems, and they should attenuate or eliminate the relationship between self-reported behavior and the IAT. The associative interpretation of the IAT predicts the same IAT effect in both familiarity conditions and does not expect an attenuation of the relationship between alcohol use and IAT effects by FG asymmetries.

\section{Method}

\section{Participants}

Forty-six students of Maastricht University (11 men, 35 women; mean age $=21.6$ years, $S D=2.25$ ) participated in the study for course credit. On the Alcohol Use Disorder Identification Test (AUDIT; Saunders, Aasland, Babor, De la Fuente, \& Grant, 1993), participants' mean score was 9 $(S D=4.54)$, which is comparable to American college students (Fleming, Barry, \& MacDonald, 1991). About $60 \%$ of the participants scored 8 or higher on the AUDIT, and about $30 \%$ scored 11 or higher, which are the respective cut-off scores for being a hazardous drinker and for the screening of alcohol problems (Saunders et al., 1993). On average, participants drank alcohol about once a week, with three to four alcoholic drinks on each occasion, and had a binge almost once a month.

\section{Materials and Measures}

\section{Alcohol Use and Problems}

Alcohol use and alcohol-related problems were assessed with the AUDIT (Saunders et al., 1993). The AUDIT consisted of 10 questions in a multiple-choice format. The first three questions related to alcohol use $(\alpha=.80)$, the other seven to alcohol-related problems $(\alpha=.83)$.

\section{Implicit Association Task}

The selection of the IAT alcohol and soft drink targets was based on a pilot study with the same participants approximately a week before the test. A number of alcoholic drinks and soft drinks were rated on familiarity on a 7 point Likert scale $(1=$ never seen/heard about, $7=$ very often seen/heard about). The five most familiar and the five most unfamiliar alcoholic drinks $(M=5.31, S D=1.17$ and $M=2.34, S D=.76$, respectively) were selected for the unfamiliar and familiar alcohol categories. The same procedure was followed for the soft drink categories (familiar soft drinks: $M=5.85, S D=.87$; unfamiliar soft 
drinks: $M=2.06, S D=.73$ ). Evaluative ratings, obtained from a subsample of the participants in the present study $(N=17)$, showed that both unfamiliar alcohol and unfamiliar soft drink stimuli were evaluated as neutral $(M=$ $3.61, S D=.67$ and $M=4.06, S D=.88$, respectively). Familiar alcohol stimuli were also evaluated as neutral $(M$ $=4.41, S D=.99)$, whereas familiar soft drink stimuli were more positively evaluated $(M=5.28, S D=1.02)$. Paired-samples $t$-tests confirmed that there was no significant difference in valence between the familiar alcohol and the unfamiliar soft drink category, $t(16)=1.24, p=.235$, whereas the familiar soft drink category was evaluated as significantly more positive than the unfamiliar alcohol category, $t(16)=-5.507, p<.001$. Valence words were identical to those used by Wiers et al. (2002). All stimuli are presented in the Appendix.

Participants performed one of two IAT versions: the IAT with familiar alcohol vs. unfamiliar soft drink or the IAT with unfamiliar alcohol vs. familiar soft drink. Both IATs were programmed in ERTS 3.18 (Beringer, 1996), modeled after the IAT by Greenwald et al. (1998). Both IAT versions consisted of five blocks. Participants first received 20 trials of target-discrimination practice in which all targets were presented twice. Next, they performed 20 trials of attribute-classification practice. The third block was the combination block during which both target and attribute stimuli were presented for 40 trials. Next, participants practiced the reversed attribute discrimination, followed by the reversed combination block. The intertrial interval was 250 milliseconds. Feedback ("wrong," "too fast" $[<300 \mathrm{~ms}]$, and "too slow" [>3,000 ms]) was presented. Internal consistencies, calculated as in Greenwald et al. (2003), were .84 for the familiar alcohol IAT, and .87 for the unfamiliar alcohol IAT.

\section{Visual Search Task}

Participants performed two visual search tasks: one visual search task assessed salience asymmetries between the alcohol and soft drink categories and the other between the valence categories. Participants performed the visual search tasks with the same stimuli as in the IAT. Visual search tasks were programmed in ERTS 3.18 (Beringer, 1996), exactly following Rothermund and Wentura (2004). First, participants received 20 categorization trials to practice the assignment of stimuli to their respective categories. Immediately after the practice block, the corresponding visual search task was performed, consisting of 12 practice trials and 64 experimental trials. During each trial, four stimuli were presented. On half of the trials, all stimuli belonged to the same category ("same" trials), whereas in the other half, three stimuli belonged to one category and the fourth stimulus belonged to the other category ("different" trials). Participants were instructed to indicate with two response keys whether all stimuli on screen belonged to the same category or whether one of the stimuli belonged to a different category. On half of the trials, the majority of the stimuli (three or four out of four) belonged to the first category of the respective dimension; on the other half, the majority of the stimuli belonged to the second category. Stimuli were presented in the corners of either a virtual square or a virtual diamond. During "different" trials, the stimulus that differed appeared twice at each of the four possible locations. Each trial started with a ready signal ("X") in the middle of the screen, which was replaced by a cue ("“") when participants pressed the space bar. After an interval of $500 \mathrm{~ms}$, the stimuli were presented around the cue in black against a grey background. Response labels ("same" and "different") were presented in the upper right and left corners of the computer screen. Stimulus words remained on screen until the correct response was given. Feedback ("ERROR - press correct key and continue") was presented until the correct response was given.

\section{Alcohol Expectancy Questionnaire}

The alcohol expectancy questionnaire consisted of 10 items, of which 5 items referred to positive expectancies $(\alpha=.87)$ and 5 items represented negative expectancies $(\alpha=.84)$. Positive and negative expectancies were negatively correlated, $r(46)=-.39, p=.008$. Each item asked participants to indicate on a Visual Analogue Scale (VAS) how much they agreed or disagreed with the following statement: "After drinking alcohol, I feel ..." which was completed with the same positive and negative words as presented during the IAT.

\section{Design and Procedure}

After signing the informed-consent form, participants randomly performed the familiar alcohol IAT or the unfamiliar alcohol IAT. The assignment of alcohol and soft drink target categories to the response keys was balanced across participants. Half of the participants received the alcoholnegative combination (compatible response assignment) first and then the alcohol-positive combination (incompatible response assignment) ( $\mathrm{CR}$ condition), and half received the reversed order of combination tasks ( $\mathrm{RC}$ condition; see Greenwald et al., 1998). Next, participants performed the two visual search tasks. The response assignment of same and different trials was balanced across participants as well as the order of the visual search tasks. Participants then filled out the alcohol expectancy questionnaire and the AUDIT.

\section{Results}

\section{Implicit Association Task}

IAT effects were calculated with both the conventional measure in ms (Greenwald et al., 1998) and the new D600 measure (Greenwald et al., 2003).' First, for each participant, mean response latencies were calculated separately for the compatible and incompatible response assignments. Next, the conventional ms measure of IAT effects was calculated as the difference between these two means in such a way that higher IAT scores indicated faster performance

1 We analyzed both the conventional scoring algorithm (ms) and the new D600 algorithm and have reported results with both measures of 
for the compatible (alcohol + negative vs. soft drink + positive) than for the incompatible (alcohol + positive vs. soft drink + negative) combination task. The D600 measure of IAT effects was calculated in the same direction as the conventional ms IAT measure. Further, following the formula presented by Greenwald et al. (2003), practice blocks were now included, error penalties $(600 \mathrm{~ms})$ were given in case of a wrong response, and results were standardized at the level of the participant.

Both IAT effect measures were entered in a 2 (familiarity) $\times 2$ (order of combination tasks: $\mathrm{CR}$ or RC) univariate analysis of variance (ANOVA). Results for the D600 measure showed a significant order effect, $F(1,42)=6.35, p$ $=.016, \eta=.13$, but no significant effect of familiarity, $F(1,42)=1.90, p=.176$, in the absence of a significant interaction $(p>.80)$. For the conventional ms measure, results showed both a significant effect of familiarity, $F(1$, $42)=4.81, p=.034, \eta=.10$, and of order, $F(1,42)=$ $11.29, p=.002, \eta=.21$, in the absence of an interaction effect $(p>80)$. Next, IAT effects were analyzed separately for both orders of combination tasks and separately for both familiarity conditions with one-sample $t$-tests. Mean response latencies for compatible and incompatible combination tasks and mean IAT effects are presented per combination task order and per familiarity version in Table 1. In the CR condition, both the D600 and the ms measure of the IAT effect were highly significant, $t(20)=5.31, p$ $<.001, d=1.16$ and $t(20)=5.23, p<.001, d=1.14$, respectively, indicating that performance was faster for the combination of alcohol and negative than for the combination of alcohol and positive. In the RC condition, this IAT effect was smaller, but still significant for the conventional ms measure, $t(24)=2.22, p=.036, d=.45$, while borderline significant for the D600 measure, $t(24)=1.82$, $p=.081, d=.36$. Next, IAT effects were analyzed per familiarity condition. Results showed that IAT effects measured with both the D600 and the conventional ms measure were significant in the unfamiliar alcohol IAT condition, $t(21)=4.08, p=.001, d=.87$ and $t(21)=5.20, p<$ $.001, d=1.11$, respectively, and were smaller but still significant in the familiar alcohol IAT condition, $t(23)=$ $2.46, p=.022, d=.50$ and $t(23)=2.27, p=.033, d$ $=.46$, respectively. These results indicate that, in both familiarity conditions, performance was faster when alcohol and negative were mapped onto the same response than when alcohol and positive shared a response. In sum, results with both IAT scoring algorithms indicate that performance was faster for the combination of alcohol and negative words than for the combination of alcohol and positive words, in both combination task-order conditions and in both familiarity conditions.

\section{Salience Asymmetries}

Following Rothermund and Wentura (2004), trials with erroneous responses were left out of the analyses. For each visual search task, mean response latencies were computed for trials in which the majority of the stimuli (distractors) belonged to the first or second category of the respective dimension (e.g., alcohol or soft drink). This was done separately for same and different trials because same trials have been found to be a more sensitive indicator of FG asymmetries (Rothermund \& Wentura, footnote 5). Furthermore, mean response latencies were log-transformed before analyses. As can be seen in Figure 1, responding was significantly slower for trials with unfamiliar soft drink distractors than for trials with familiar alcohol distractors, $t(23)=-10.11, p<.001, d=2.06$ and $t(23)=-3.17$, $p=.004, d=.65$, for same and different trials, respectively. Responding was also significantly slower for same trials with unfamiliar alcohol distractors compared with same trials with familiar soft drink distractors, $t(21)=$ $2.57, p=.018, d=.55$. However, no salience asymmetry between unfamiliar alcohol and familiar soft drink was found for the different trials, $t(21)=1.62, p=.121$. Further, in the familiar alcohol condition, results demonstrated significantly slower responses for same trials with negative distractors compared with same trials with positive distractors, $t(23)=8.48, p<.001, d=1.73$, while this salience asymmetry was borderline significant for different trials, $t(23)=1.98, p=.059$. Similarly, in the unfamiliar alcohol condition, processing negative words was significantly slower than processing positive words during both same trials, $t(21)=7.94, p<.001, d=1.69$, and different trials, $t(21)=6.03, p<.001, d=1.29$. Hence, consistent with the hypotheses, the unfamiliar alcohol and soft drink target categories were more salient than the familiar alcohol and soft drink target categories, and the negative attribute category was more salient than the positive attribute category.

Before entering FG asymmetries in correlational analyses, difference scores were computed separately for same and different trials, by subtracting mean log-transformed response latencies for trials with soft drinks and positive distractors from mean log-transformed response latencies for trials with alcohol and negative distractors, respectively. Therefore, positive difference scores indicated that alcohol and negative stimuli were more salient than soft drink and positive stimuli, respectively. To test whether the IAT was confounded with these FG asymmetries, partial correlations, controlled for order of IAT combination tasks, were computed between the IAT and FG asymmetries. Partial correlations between the IAT and FG asymmetries for the whole sample as well as per familiarity condition are shown in Table 2. Overall, a significant correlation was found between the conventional ms measure of IAT effects and salience asymmetries between alcohol and soft drink on same trials. When partial correlations were computed per familiarity condition, this correlation was more pronounced for the familiar alcohol condition than for the unfamiliar alcohol condition, but it did not reach statistical significance in either familiarity condition. No significant correlations emerged between salience asymmetries and the D600 measure of IAT effects.

IAT effects. There are three reasons for doing this: First, the new D600 measure has been found to yield different results than the conventional ms measure (e.g., Wiers et al., 2005). Second, there is no consensus regarding the optimal measure for IAT effects (see Greenwald et al., 2005, vs. Rothermund et al., 2005). Third, using the ms measure enables comparison with earlier IAT research and methods. 
Table 1. Mean response latencies in compatible and incompatible combination tasks and mean IAT effects (standard deviations in parentheses)

\begin{tabular}{|c|c|c|c|c|c|}
\hline \multirow[b]{2}{*}{ Variable } & & \multicolumn{2}{|l|}{ Combination Task } & \multicolumn{2}{|l|}{ IAT effect } \\
\hline & & Compatible & Incompatible & Conventional ms measure & D600 measure \\
\hline \multirow[t]{2}{*}{ Familiarity } & Familiar alcohol & $708.30(153.21)$ & $819.39(211.00)$ & $111.09(240.29)$ & $.47(.94)$ \\
\hline & Unfamiliar alcohol & $637.81(90.12)$ & $886.50(234.69)$ & $248.69(224.54)$ & $.83(.96)$ \\
\hline \multirow[t]{2}{*}{ Order } & $\mathrm{CR}$ & $689.06(124.76)$ & $980.34(240.28)$ & $291.28(255.48)$ & $1.01(.87)$ \\
\hline & $\mathrm{RC}$ & $662.43(136.64)$ & $743.25(134.80)$ & $80.82(181.79)$ & $.34(.93)$ \\
\hline
\end{tabular}

Note. Mean response latencies and mean IAT effects are shown separately for both familiarity conditions (familiar alcohol and unfamiliar alcohol) and both combination task orders ( $\mathrm{CR}$ and $\mathrm{RC}) . \mathrm{CR}=$ compatible combination task first, $\mathrm{RC}=$ incompatible combination task first. In the compatible combination task, alcohol and negative words were assigned to the same response, whereas alcohol and positive words shared a response in the incompatible combination task. The conventional IAT-effect measure in ms was computed as the difference between the means for the compatible and incompatible combination tasks. The D600 IAT-effect measure was calculated by dividing this difference score by the standard deviation of all response latencies in both combination tasks.

\section{Alcohol Expectancies}

Mean scores were calculated for the positive expectancy items and the negative expectancy items. Participants' mean score for the positive expectancies was significantly higher than the neutral midpoint of the scale, $t(45)=7.01$, $p<.001, d=1.03$, whereas their mean score for the negative expectancies was significantly lower than the neutral midpoint, $t(45)=-14.76, p<.001, d=2.18$. Hence, participants expected positive effects from drinking alcohol on explicit measures. Partial correlations between expectancies and IAT effects, controlled for order of IAT combination tasks, are presented in Table 2 . Overall, only the negative correlation between the ms measure of IAT effects and positive expectancies reached statistical significance, indicating that participants who endorsed more positive alcohol expectancies also showed a smaller IAT effect. When partial correlations were calculated separately for the two familiarity conditions, the unfamiliar alcohol IAT was found to be negatively correlated with positive expectancies, although this was significant only for the conventional IAT measure and uncorrelated with negative expectancies. The familiar alcohol IAT correlated negatively with both positive and negative expectancies although this was not statistically significant for both IAT measures.

\section{Alcohol Use and Problems}

Estimates of alcohol use and alcohol-related problems were calculated as the sum scores of items 1 to 3 and items 4 to 10 in the AUDIT, respectively. The alcohol-related problems estimate was then log-transformed to obtain normality. Partial correlations of alcohol use and alcohol-related problems with IAT effects, controlled for order of IAT combination tasks, are presented in Table 2. Overall, the IAT was correlated negatively with both alcohol use and problems, indicating that participants who showed a smaller IAT effect consumed more alcohol and experienced more alcohol-related problems. When correlations were analyzed separately for the two familiarity conditions, only the familiar alcohol IAT was significantly correlated with both alcohol use and problems. In contrast, positive and negative expectancies were only borderline significantly correlated with alcohol use, $r=.28, p=.059$ and $r=-.25, p=.094$, respectively, and were uncorrelated with alcohol-related problems $(p>.30)$.

The FG account predicts that FG asymmetries will predict IAT effects above self-reported alcohol use and alcohol-related problems and that the relationship between IAT effects and self-report measures will be attenuated by FG asymmetries. These predictions were tested in hierarchical multiple regression analyses. IAT effects were entered as the dependent variable in different regression analyses, performed separately for the two familiarity conditions, to examine whether entering FG asymmetries as a predictor of IAT effects would influence the prediction by alcohol use and alcohol-related problems. The first run of the hierarchical regression analysis for the familiar alcohol condition showed that self-reported alcohol use significantly predicted IAT effects in this condition and that entering FG asymmetries into the equation did not eliminate or attenuate this prediction. In the second run of the regression analysis, all variables that were not predictive of IAT effects $(p>.30)$ were left out. Results for this second run of the regression analysis again showed that alcohol use significantly predicted IAT effects in the familiar alcohol condition and that FG asymmetries between the alcohol and soft drink categories on same trails did not predict IAT effects, nor did they eliminate the prediction of IAT effects by alcohol use (see Table 3). In the unfamiliar alcohol condition, neither the self-report measures nor FG asymmetries significantly predicted IAT effects. ${ }^{2}$

Next, it was examined whether the IAT predicted alcohol use above gender, age, and explicit expectancies in the familiar alcohol condition. Note that in this hierarchical regression analysis, the IAT was entered as an independent variable instead of a dependent variable. This is because the hierarchical regression analyses reported previously tested whether IAT effects were determined more by FG asymmetries than by self-report measures in a manner

2. This table is not shown here, but is available upon request. 

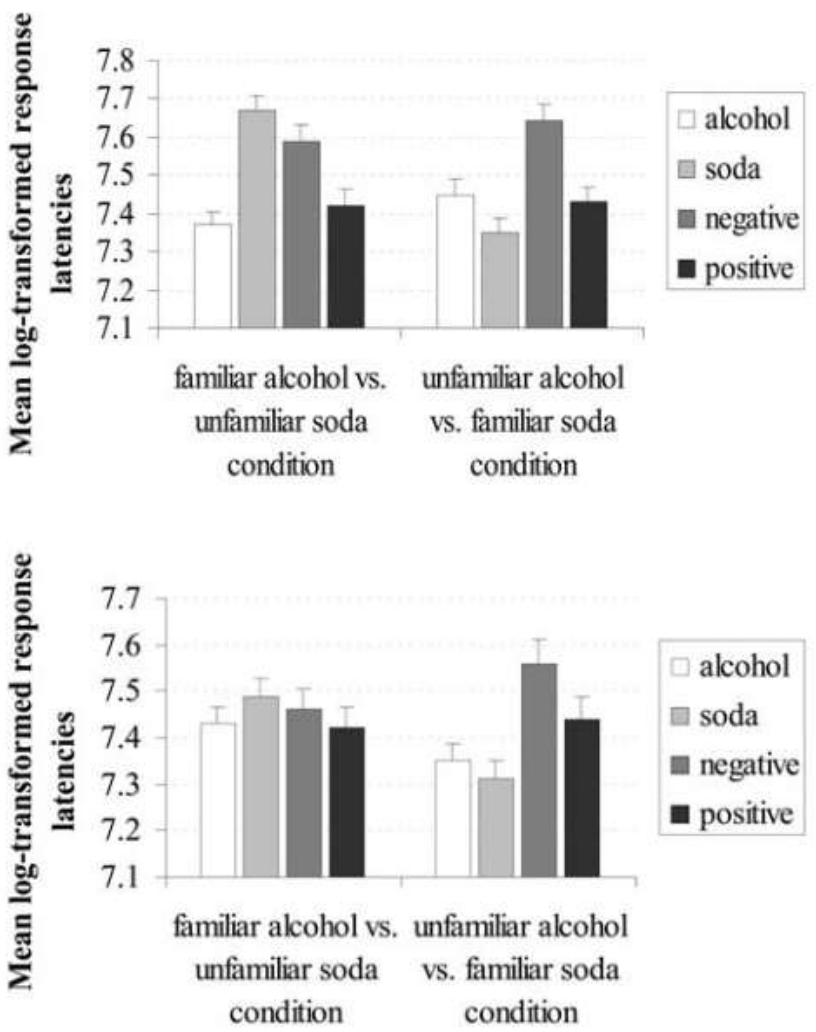

Figure 1. Log-transformed mean response latencies for each category presented in the visual search task are shown separately for the two familiarity conditions. Visual search tasks examined salience asymmetries either between the alcohol and soft drink target categories or between the positive and negative attribute categories. Log-transformed response latencies are also shown separately for "same" (top) and "different" (bottom) search trials. In "same" trials, participants responded to four stimuli that all belonged to the same category (e.g., four alcohol stimuli during an alcohol "same" trial), whereas on "different" trials, participants responded to three distractors from one category and one target from the other category (e.g., three alcohol stimuli and one soft drink stimulus during an alcohol "different" trial). Longer response latencies for a category compared with the other indicate that this category was more salient than the other category.

similar to the analyses reported by Rothermund and Wentura (2004), whereas the following regression analysis examined the incremental validity of the familiar alcohol IAT above explicit measures in the same way as Wiers et al. (2002). In step 1 of the hierarchical regression analysis, gender significantly predicted alcohol use $(\beta=-.59, p$ $=.008)$ whereas age did not $(\beta=-.32, p=.131), F(2$, 21) $=4.35, p=.026, R^{2}=.29$. Positive and negative expectancies were entered in step 2 , which did not increase the variance explained, $F_{\text {change }}(2,19)=.56, p=.580$, $R_{\text {change }}^{2}=.04$. Finally, the IAT was entered in step 3 and significantly predicted alcohol use above the background variables, both when the conventional ms IAT-effect mea- sure was entered as a predictor, $F_{\text {change }}(1,18)=8.12, p=$ $.011, R_{\text {change }}^{2}=.21$, and when the D600 measure was used, $F_{\text {change }}(1,18)=.7 .89, p=.012, R_{\text {change }}^{2}=.20^{2}$.

\section{Discussion}

Previous alcohol-IAT studies have repeatedly shown the counterintuitive finding that drinkers are faster to combine both alcohol and negatively valenced words than alcohol and positively valenced words in the IAT, while they, in contrast, indicate to be positive about alcohol on explicit measures (e.g., Houben \& Wiers, 2006; Wiers et al., 2002, 2005 ; this study). Here, it was tested whether this puzzling finding might reflect FG asymmetries, rather than meaningful associations between alcohol and negative valence. The FG account of the negative alcohol-IAT effect was tested in two ways. First, it was examined whether a familiarity manipulation designed to reverse $\mathrm{FG}$ asymmetries between IAT target categories would also reverse the negative alcohol-IAT effect as predicted by the FG account. Second, it was tested whether the IAT effect would be correlated with independently assessed FG asymmetries and whether these FG asymmetries would diminish the relationship between the IAT and alcohol use and alcoholrelated problems.

Considering the present pattern of results, it can be concluded that some aspects of the data corroborate the FG account of the alcohol IAT whereas others do not. First, in line with the FG account, the familiarity manipulation influenced IAT effects in the expected direction: in the familiar alcohol-IAT where both the (unfamiliar) soft drink target category and the negative attribute category were figures, the negative alcohol-IAT effect was smaller than in the unfamiliar alcohol-IAT were the (unfamiliar) alcohol target category and the negative attribute category were figures. Also, the salience asymmetry between the alcohol and soft drink categories was correlated with the conventional ms measure of IAT effects, indicating that the ms IAT effect increased as alcohol became more salient than soft drink. Thus, consistent with the FG account, this correlation implies that it was easier to combine alcohol and negative words (which was always the figure category compared with the positive attribute category) in the IAT when alcohol was a figure category compared to soft drink. However, importantly and in contrast to the prediction by the FG account, the familiarity manipulation was insufficient to reverse the alcohol-negative IAT effect (as was demonstrated for other IATs by Rothermund \& Wentura, 2004). Furthermore, in support of the validity of the IAT, IAT effects in the familiar alcohol condition were predicted by self-reported alcohol use, and FG asymmetries did not render this prediction nonsignificant. Also, the familiar alcohol IAT predicted alcohol use above background variables and explicit expectancy measures. In contrast, the unfamiliar alcohol IAT was not predictive of alcohol use, which is not surprising given that the unfamiliar alcohol (and soft drink) targets presented in this IAT were probably drinks that were never consumed by the participants.

It is important to note that whereas alcohol-IAT effects 


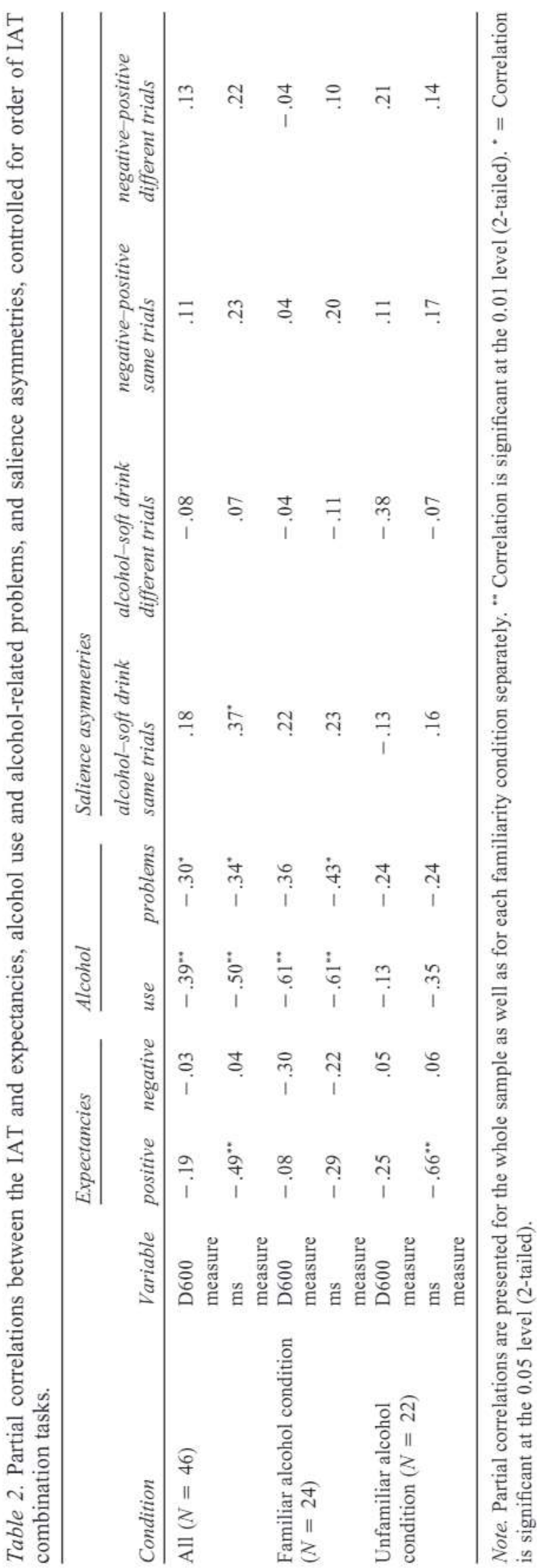

in the present study were influenced by the familiarity of the target concepts, other studies have not found noticeable effects of familiarity manipulations on results with ingroup-outgroup IATs (e.g., Dasgupta, McGhee, Greenwald, \& Banaji, 2000; Ottaway, Hayden, \& Oakes, 2001; Rudman, Greenwald, Melliot, \& Schwartz, 1999). However, the aim of the present study was to examine the effect of FG asymmetries caused by differential familiarity of the target categories alcohol and soft drink on IAT effects. In contrast, Ottaway et al. (2001) contrasted either two familiar target categories or two unfamiliar target categories and, thus, did not create a FG asymmetry that was based on familiarity. Furthermore, studies by both Rudman et al. (1999) and Dasgupta et al. (2000) were mainly focused on examining whether IAT effects could be due to greater familiarity of ingroup stimuli compared to outgroup stimuli and demonstrated no influence of differential familiarity on IAT scores. However, in both studies, familiarity measures for both target categories were combined into a relative familiarity measure in such a way that higher scores indicated greater familiarity with ingroup stimuli than with outgroup stimuli. Hence, it is possible that outgroup stimuli, although less familiar than ingroup stimuli, were not sufficiently unfamiliar to create a FG asymmetry.

The difference in results with the D600 measure and the conventional ms measure is directly related to the ongoing discussion about the suitability of both measures as measures of IAT effects. In agreement with Greenwald et al. (2005), the present results suggest that the ms measure is more sensitive to FG effects than is the D600 measure. However, similar to what is argued by Rothermund et al. (2005), the present results also imply that the D-measure is not immune to FG effects.

A limitation to the present results is that valence was not controlled, which can also be a contributor to FG asymmetries in the IAT (Rothermund \& Wentura, 2004). Valence ratings of the alcohol and soft drink stimuli obtained from a subset of participants showed that there was no significant difference in valence between the familiar alcohol and unfamiliar soft drink categories, implying that salience asymmetries between this contrasted pair were based on the familiarity manipulation and not on valence. However, familiar soft drink stimuli were evaluated more positively than unfamiliar alcohol stimuli, implying that the unfamiliar alcohol category was more salient than the familiar soft drink category because it was both more unfamiliar and more negative than the familiar soft drink category.

The present results are consistent with previous alcoholIAT studies in which familiarity of the target categories was properly matched (well-known alcoholic drinks and soft drinks): the negative-alcohol IAT effect is typically only weakly correlated with direct self-report measures of attitudes and expectancies (e.g., Houben \& Wiers, in press; Wiers et al., 2002, 2005) and has been found to be sensitive to differences in alcohol consumption (e.g., Wiers et al., 2002). Furthermore, with respect to the alcohol targets, the familiar alcohol IAT was highly similar to previous alcohol IATs. However, the difference with previous alcohol IATs concerned the now unfamiliar soft drink category. This manipulation resulted in a smaller IAT effect than reported in 
Table 3. Summary of hierarchical regression analysis for the prediction of IAT effects by self-reported alcohol use and alcohol-related problems and FG asymmetries, in the familiar alcohol condition.

\begin{tabular}{|c|c|c|c|c|c|c|c|}
\hline Step & Variable & B & $S E$ B & $\beta$ & $S E \beta$ & $t$ & $p$ \\
\hline \multicolumn{8}{|c|}{ First run } \\
\hline \multirow[t]{2}{*}{1} & Alcohol use & -51.34 & 16.69 & -.58 & .19 & -3.08 & .006 \\
\hline & Alcohol-related problems & -15.30 & 58.07 & -.05 & .19 & -0.26 & .795 \\
\hline \multirow[t]{6}{*}{2} & Alcohol use & -56.48 & 17.47 & -.64 & .20 & -3.23 & .005 \\
\hline & Alcohol-related problems & 13.98 & 63.37 & .05 & .21 & 0.22 & .828 \\
\hline & FG alcohol-soft drink same & 420.36 & 317.17 & .25 & .19 & 1.33 & .203 \\
\hline & FG alcohol-soft drink different & 186.43 & 499.05 & .07 & .19 & 0.37 & .713 \\
\hline & FG negative-positive same & 398.96 & 461.04 & .17 & .20 & 0.87 & .399 \\
\hline & FG negative-positive different & -114.42 & 396.84 & -.06 & .19 & -0.29 & .777 \\
\hline \multicolumn{8}{|c|}{ Second run } \\
\hline 1 & Alcohol use & -53.12 & 14.93 & -.60 & .17 & -3.56 & .002 \\
\hline 2 & FG alcohol-soft drink same & 448.47 & 270.46 & .27 & .16 & 1.66 & .112 \\
\hline
\end{tabular}

Note. All variables that were not predictive $(p>.30)$ of IAT effects in the first run of the regression analysis were left out in the second run of the analysis. Results are shown for the conventional ms IAT effect measure. Results for the D600 IAT measure were generally the same and are available upon request.

For the first run of the regression analysis, $F(2,21)=6.10, p=.008, R^{2}=.37$ for step $1 ; F_{\text {change }}(4,17)=.77, p=.562, R_{\text {change }}^{2}=$ .10 for step 2. For the second run of the analysis, $F(1,22)=12.67, p=.002, R^{2}=.37$ for step $1 ; F_{\text {change }}(1,21)=2.75, p=.112$, $R_{\text {chunge }}^{2}=.07$ for step 2 .

previous alcohol-IAT studies. In contrast, the unfamiliar alcohol IAT was similar to previous alcohol IATs with respect to the (familiar) soft drink targets. Here, the IAT effect size was comparable to previous alcohol-IAT results. There are a number of reasons for this, including the possibility that a meaningful FG asymmetry could exist between the alcohol and soft drink categories in heavy drinkers because of an alcohol-related attentional bias that increases the salience of alcohol-related stimuli (see Field, Mogg, \& Bradley, 2006). Therefore, when using the alcohol IAT, it is important to supplement the IAT with visual search tasks in order to assess possible FG asymmetries and to control for their influence on IAT effects. Nevertheless, the present results also show that FG asymmetries between the alcohol and soft drink target categories cannot completely account for the negative alcohol-IAT effect because no reversal of the IAT effect was found as would be predicted by the FG account.

Instead, the possibility was raised that the negative alcohol-IAT effect could be representative of problems related to alcohol use (e.g., Wiers et al., in press). However, the direction of the correlation between the IAT and alcohol-related problems was not in agreement with this account. Also, the negative alcohol-IAT effect could reflect early, negative experiences with alcohol whereas explicit measures may be more related to recent experiences (Rudman, 2004). Although this possibility was not tested in the present study, another study found no support for this hypothesis (Houben \& Wiers, in press). Another possibility could be that the IAT effect does not reflect an association between alcohol and negative expected outcomes, but between alcohol and a negative antecedent mood state. This temporal sequence of associations is not addressed by the IAT, but can be examined with other techniques such as semantic and affective priming procedures (cf. Zack, Toneatto, \& Macleod, 1999).
Future research should further examine the validity of the FG interpretation of IAT effects in different areas of experimental research, including psychopathology where FG asymmetries might be meaningful contributors to IAT effects. Also, researchers should remain attentive to the possible influence of salience asymmetries on IAT effects, and therefore, in agreement with Rothermund and Wentura (2004), it is recommended to supplement the IAT with visual search tasks to examine whether salience asymmetries are present within the IAT dimensions and to control for salience effects.

\section{Acknowledgments}

Katrijn Houben and Reinout W. Wiers, Experimental Psychology, Faculty of Psychology, Maastricht University, The Netherlands. Both authors are funded by "VIDI" grant 452.02.005 from the Dutch National Science Foundation (N.W.O.) awarded to the second author.

The authors wish to thank Noortje Beks, Rebecca Kuepper, Wout Maris, Anke Wevers, and Ralph Wilms for their assistance in carrying out the study as well as Anne Roefs and Rob Ruiter for their comments on an early draft of the manuscript.

\section{References}

Beringer, J. (1996). Experimental Run Time System (ERTS), Version 3.18. Frankfurt, Germany: BeriSoft.

Bosson, J. K., Swann, W. B., \& Pennebaker, J. W. (2000). Stalking the perfect measure of implicit self-esteem: The blind men and the elephant revisited? Journal of Personality \& Social Psychology, 79, 631-643.

Cunningham, W. A., Preacher, K. J., \& Banaji, M. R. (2001). Implicit attitude measures: Consistency, stability, and convergent validity. Psychological Science, 12, 163-170. 
Dasgupta, N., McGhee, D. E., Greenwald, A. G., \& Banaji, M. R. (2000). Automatic preference for white Americans: Eliminating the familiarity explanation. Journal of Experimental Social Psychology, 36, 316-328.

De Houwer, J., Crombez, G., Koster, E.H.W., \& De Beul, N. (2004). Implicit alcohol-related cognitions in a clinical sample of heavy drinkers. Journal of Behavior Therapy \& Experimental Psychiatry, 35, 275-286.

Field, M., Mogg, K., \& Bradley, B. P. (2006). Attention to drugrelated cues in drug abuse and addiction: component processes. In R. W. Wiers \& A. W. Stacy (Eds.), Handbook of Implicit Cognition and Addiction (pp. 151-163). Thousand Oakes, CA: Sage.

Fleming, M. F., Barry, K. L., \& MacDonald, R. (1991). The alcohol use disorders identification test (AUDIT) in a college sample. The International Journal of the Addictions, 26, 1173 1185 .

Greenwald, A. G., McGhee, D. E., \& Schwartz, J.L.K. (1998). Measuring individual differences in implicit cognition: The implicit association test. Journal of Personality \& Social Psychology, 74, 1464-1480.

Greenwald, A. G., Nosek, B. A., \& Banaji, M. R. (2003). Understanding and using the implicit association test: I. An improved scoring algorithm. Journal of Personality \& Social Psychology, 85, 197-216.

Greenwald, A. G., Nosek, B. A., Banaji, M. R., \& Klauer, K. C. (2005). Validity of the salience asymmetry interpretation of the IAT: Comment on Rothermund and Wentura (2004). Journal of Experimental Psychology: General, 134, 420-425.

Hofmann, W., Gawronski, B., Gschwendner, T., Le, H., \& Schmitt, M. (2005). A meta-analysis on the correlation between the implicit association test and explicit self-report measures. Personality \& Social Psychology Bulletin, 31, 1369 1385.

Houben, K., \& Wiers, R. W. (2006). Assessing implicit alcohol associations with the IAT: Fact or artifact? Addictive Behaviors, 31, 1346-1362.

Nosek, B. A., Greenwald, A. G., \& Banaji, M. R. (in press). The Implicit Association Test at age 7: A methodological and conceptual review. In J. A. Bargh (Ed.), Social psychology and the unconscious: The automaticity of higher mental processes. New York: Psychology Press.

Ottaway, S. A., Hayden, D.C., \& Oakes, M. A. (2001). Implicit attitudes and racism: Effects of word familiarity and frequency on the Implicit Association Test. Social Cognition, 19, 97-144.

Poehlman, T. A., Uhlmann, E., Greenwald, A. G., \& Banaji, M. R. (2004). Understanding and using the Implicit Association Test: III. Meta-analysis of predictive validity. Manuscript submitted for publication.

Rothermund, K., \& Wentura, D. (2004). Underlying processes in the Implicit Association Test: Dissociating salience from associations. Journal of Experimental Psychology: General, 133, 139-165.

Rothermund, K., Wentura, D., \& De Houwer, J. (2005). Validity of the salience asymmetry account of the IAT: Reply to Greenwald, Nosek, Banaji, and Klauer (2005). Journal of Experimental Psychology: General, 134, 426-430.

Rudman, L. A. (2004). Sources of implicit attitudes. Current Directions in Psychological Science, 13, 79-82.

Rudman, L. A., Greenwald, A. G., Melliot, D. S., \& Schwartz, J.L.K. (1999). Measuring the automatic components of prejudice: Flexibility and generality of the Implicit Association test. Social Cognition, 17, 437-465.

Saunders, J. B., Aasland, O. G., Babor, T. F., De la Fuente, J. R., \& Grant, M. (1993). Development of the Alcohol use Disorders Identification Test (AUDIT): WHO collaborative project on early detection of persons with harmful alcohol consumption. Addiction, 88, 791-804.

Wiers, R. W., Houben, K., Smulders, F. T. Y., Conrod, P. J., \& Jones, B. T. (2006). To drink or not to drink: The role of automatic and controlled processes in the etiology of alcoholrelated problems. In R. W. Wiers \& A. W. Stacy (Eds.), Handbook of Implicit Cognition and Addiction (pp. 339-361). Thousand Oaks, CA: Sage.

Wiers, R. W., van de Luitgaarden, J., van den Wildenberg, E., \& Smulders, F.T.Y. (2005). Challenging implicit and explicit alcohol-related cognitions in young heavy drinkers. Addiction, $100,806-819$.

Wiers, R. W., Van Woerden, N., Smulders, F.T.Y., \& de Jong, P. J. (2002). Implicit and explicit alcohol-related cognitions in heavy and light drinkers. Journal of Abnormal Psychology, 111, 648-658.

Zack, M., Toneatto, T., \& Macleod, C. M. (1999). Implicit activation of alcohol concepts by negative affective cues distinguishes between problem drinkers with high and low psychiatric distress. Journal of Abnormal Psychology, 108, 518-531.

\section{Appendix}

\section{IAT Target Stimuli}

Alcohol (familiar): beer, wine, Baileys, Bacardi, martini

Alcohol (unfamiliar): vieux, absinth, batida de coco, Tia Maria, fiero

Soda (familiar): iced tea, apple juice, Fanta, Spa (mineral water), Coke

Soda (unfamiliar): Roosvicee (syrup), Karvan Cevitam (syrup), Water Joe, Breaker (yogurt drink), carrot juice

\section{IAT Attribute Stimuli}

Positive: social, good, pleasant, nice, enjoyable

Negative: antisocial, bad, unpleasant, stupid, obnoxious

Katrijn Houben

Experimental Psychology

Maastricht University

PO Box 616

NL-6200 MD Maastricht

The Netherlands

E-mail K.Houben@psychology.unimaas.nl 